\title{
Role of Job Satisfaction in Managing Sexual Satisfaction, Self Esteem and Mental Health at Work Place
}

\author{
Avik Bhattacharjee $^{1 *}$, Atreye Kundu ${ }^{2}$, Dr. Indrani Mukherjee ${ }^{3}$
}

\section{ABSTRACT}

The purpose of the present study to examine the role of job satisfaction on sexual satisfaction, self-esteem and mental health in corporate workers. The statistics include all employees of an IT company in the city of KOLKATA. The sample of 150 people was selected randomly for the study. From the total sample 75 males \& 75 females were asked to complete questionnaires of above mentioned 4scales. Each group of males and females was consisted respondents age ranging between 30-35years. The tenure of the job was within 7 to 12 years. Both graduates \& post-graduate employees were selected. All were married and their income range was in between 40,000 to 60,000. Data was analysis using descriptive statistics i.e. Mean, SD for both group males and females. Then $\mathrm{Z}$ test, Product Moment correlation and finally linear regression were done. In case of correlation and regression the 2 groups were clubbed as the $Z$ values of all 4 variables were insignificant. Finding of the research indicated that there was a highly positive relationship between job satisfaction employees and global index of sexual satisfaction, selfesteem, and mental health. And finally it was found that sexual Satisfaction, self-esteem and mental health can predict well enough the job satisfaction of the present IT Sample.

Keywords: Job Satisfaction, Sexual Satisfaction, Self Esteem, Mental Health, Corporate Organisation (IT-Sector).

Sexual Satisfaction emanating from sexual relationship between two spouses is perhaps one of the most important dimensions of the multi-dimensional concept of marital satisfaction (Tazek and, Nafar \& Keramati; 2013).Not only that, sexual satisfaction by itself is an index of a happy marital relationship, providing mutual satisfaction \& enjoyment. According to Abraham Maslow (1954) “sex is interesting, but it's not totally important. I mean it's not even as important (physically) as excretion. A man can go seventy years without a piece of ass, but he can die in a

\footnotetext{
${ }^{1}$ Research Scholar, Dept. of Applied Psychology. Calcutta University, Guest Faculty Dept. Of Applied Psychology, Womens College Kolkata; Guest Faculty Dept. Of Psychology in Indira Gandhi National Open University, India

${ }^{2}$ Master Degree Student, Dept. of Psychology. Calcutta University, India

${ }^{3}$ Senior Professor, Dept. of Applied Psychology. Calcutta University, India

*Responding Author

(C) 2016, A Bhattachajee, A Kundu, I Mukherjee; licensee IJIP. This is an Open Access Research distributed under the terms of the Creative Commons Attribution License (http://creativecommons.org/licenses/by/2.0), which permits unrestricted use, distribution, and reproduction in any Medium, provided the original work is properly cited.
} 
week without a bowel movement”. By popular theory of hierarchical need of job satisfaction mentioned about sexual satisfaction is one of the chief component of the basic physiological need upon which the other higher order needs depend, the theory states that without the fulfillment of physiological needs like sex, food, sleep, etc. attainment of higher needs like security, love $\&$ belongingness, esteem, etc. are not possible. Keeping connection with the same, Herzbergin his Two-Factor theory proposed interpersonal relation and sexual satisfaction as hygiene factor whose absence can lead to Job satisfaction.

\section{Job Satisfaction at Work Place:}

It describes the extent of contentment of an individual with his or her job. The happier people are with their jobs, the more satisfied they are said to be. Logic would dictate that the most satisfied ('happy') workers would be the best performers and vice versa. This is called the 'happy workers"' hypothesis. However, this hypothesis is not well supported. Job Satisfaction is a very important attribute and is frequently measured by organisations. Job Satisfaction can simply be defined as the feelings of satisfaction people have about their jobs. It has been specifically defined as a pleasurable emotional state resulting from the appraisal of one's job, an affective reaction to one's job, and an attitude towards one's job. These definitions suggest that Job Satisfaction takes into account feelings, beliefs, \&behaviours.

\section{Self-Esteem at Work Place:}

Self Esteem is defined as both descriptive \& evaluative self-related statements. As a social psychological construct, Self-Esteem is attractive because researchers have conceptualised it as an influential predictor of relevant outcomes, such as academic achievement(Marsh1990)or exercise behaviour (Hagger et al.1998).In addition, self-esteem has also been treated as an important outcome due to its close relation with psychological well-being (Marsh1989).

Psychologists usually regard Self-Esteem as an enduring personality characteristic ("trait" SelfEsteem), though normal, short term variations ("state" Self- Esteem)also exist. The original normal definition presents self-esteem as a ratio found by dividing one's success in areas (of life) Important to a given individual by the failures or success in them. Problems with this approach come from making Self-Esteem contingent upon success; this implies inherent instability because failure can occur at any moment. In the 1960's, Morris Rosenberg \& Social learning theorists defined Self- Esteem in terms of a stable sense of personal worth or worthiness.

\section{LITERATURE REVIEW}

Nick Drydakis Lord Ashcroft, International Business School Anglia Ruskin University 2014 investigates the differences in four aspects of job satisfaction between different sexual orientation----- gay men/lesbians and heterosexuals. The analysis results suggest that gay men and lesbians are less satisfied with their jobs, by all job satisfaction measures, than heterosexual 
employees, all other factors being held constant. Gay men and lesbians who have disclosed their sexual orientation at their present job are more satisfied with their jobs than those who have not. Fariba Ebrahimi Tazekand, Narges Nafar, Raziye Keramatiin Life Science journal 2013 found the relationship between marital satisfaction and job satisfaction among employees of Social Welfare Organization at Tehran Branches in 2011-12.Research population included all on-thejob and married employees of Branches of social security in Tehran city. The study included 100 subjects ( 47 female and 43 male) who were selected using the simple random method.

The main hypothesis predicted a significant relationship between marital satisfaction and job satisfaction. The study was correlational .Results showed a significant relationship between marital satisfaction and job satisfaction $\mathrm{p}<0 / 05(\mathrm{r}=\mathrm{o} / 41)$. A significant difference was also found between male and female employees in marital satisfaction $(\mathrm{p}<0 / 05)$; so that male employees experienced more marital satisfaction than female ones. But in job satisfaction there was no significant difference between male and female employees $(\mathrm{p}<0 / 05)$; Hamid Reza Alavi, Mohammad Reza Askaripur in Journal citation Reports; 2016 examined the relationship between self-esteem and job satisfaction of 310 personnel in Kerman province of Iran. Two valid and reliable questionnaires, the Kruskal Wallis test and median test were used in data analysis.The result indicated that a significant relationship between self-esteem and the various factors of job satisfaction.

Seyyed Hossein Hosseini Ghafari, Masoumeh Samii in European Journal of Natural and Social Science (2013) published a significant relationship between self-esteem and job satisfaction of teachers in Aliabad University.

Karim Babayi Nadinloyi, Hasan Sadeghi, Nader Hajloo in Procedia - Social and Behavioural Sciences Volume 84, 9 July 2013, examines the relationship between job satisfaction and mental health. The statistics include all employees of two industrial companies in the city of Ardabil. The sample of 90 people was selected randomly for the study. They were asked to complete Birfield job satisfaction and Ruth questionnaire and Goldberg's general health scale. Data was analysis using multiple regressions and t-test. Finding of the research indicated that there was a positive relationship between job dissatisfaction employees and global index of mental health, social action and depression. It was found that employed women than employed men are more satisfied with their jobs. In addition, workers who have a longer history in their jobs have much job satisfaction. The results of this study, confirmed previous findings on the role of job satisfaction in the provision of mental health workers, especially to improve social relations and reduce depression. 
Role of Job Satisfaction in Managing Sexual Satisfaction, Self Esteem and Mental Health at Work Place

\section{Rationale Of The Study}

This study represents the systematic attempt to find out the role of Job Satisfaction in managing the Sexual Satisfaction, Self Esteem and Mental Health of both male and female employees at workplace. The main objectives of the study are as follow

1. To understand whether the Male and Female employees at work place differ from each other in respect of their sexual satisfaction.

2. To understand whether the Male and Female employees at work place differ from each other in respect of their Self Esteem.

3. To understand whether the Male and Female employees at work place differ from each other in respect of their Mental Health.

4. To understand whether the Sexual Satisfaction, Self Esteem \& Mental Health of both Male and Female Employees at work place are inter correlated with their job satisfaction.

5. To understand whether the predictor variable of the study namely Sexual Satisfaction, Self Esteem and Mental Health of employees at work place contribute differentially in predicting the criterion variable Job Satisfaction.

\section{Hypothesis}

Hypothesis 1-Male and Female employees at work place differ from each other in respect of their sexual satisfaction.

Hypothesis 2- Male and Female employees at work place differ from each other in respect of their Self Esteem.

Hypothesis 3-Male and Female employees at work place differ from each other in respect of their Mental Health.

If in case of no single research variable the $\mathrm{Z}$ ratio does come out to be statistically significant, then the male \& female samples will be clubbed into one single sample of data. Otherwise they will be considered as a separate sample of data from males and females respectively.

Hypothesis 4- Sexual Satisfaction, Self Esteem \& Mental Health of both Male and Female Employees at work place are inter correlated with their job satisfaction.

Hypothesis 5- The predictor variable of the study namely Sexual Satisfaction, Self Esteem and Mental Health of employees at work place contribute differentially in predicting the criterian variable Job Satisfaction.

\section{METHOD}

\section{Sample and sampling}

Study area and Sample-150 IT sectors employees across Kolkata were randomly selected as sample in this investigation. Both male \& female employees were considered. The range of age of the study group was30 years to 35years. The tenure of the job was within 7 to 12 years. Both graduates \& post-graduate employees were selected. All were married and their income range was in between 40,000 to $60,000.1$

(c) The International Journal of Indian Psychology, ISSN 2348-5396 (e)| ISSN: 2349-3429 (p) | 169 
Role of Job Satisfaction in Managing Sexual Satisfaction, Self Esteem and Mental Health at Work Place

\section{Tools and data collection}

Data for the present study have been collected by a booklet of pre-selected tools(here questioners). The following tools were used.

1. A custom-built General Information Schedule consisting of quarries about name, address, age, gender, educational qualification, income etc.

2. Original Sexual Satisfaction Scale: The scale was developed by Whitney \& Paulsen,(1975).It consists of 32 items (Likert-type) with a five point scale of responses. The questionnaire was to be self-administered. Its internal consistency reliability was $0.90 \&$ discriminant validity coefficient was 0.76.As reported by the author.

3. Job Satisfaction Survey, JSS: The scale consists of a 36 item, nine facet scale to assess employee attitudes about the job on its different aspects of the job. Each facet is assessed with four items, and a total score is computed from all items. A summated rating scale format is used, with six choices per item ranging from "'Strongly Disagree" to "' Strongly Agree". Items are written in both directions, and about half were reverse scored. The nine facets are pay, promotion, supervision, fringe benefits, contingent rewards, operating procedures, co-workers, nature of work, and communication. Although the JSS was originally developed for use in human service organisations; it is applicable to all organisations.

4. The Rosenberg Self-Esteem scale:_The scale was developed by Rosenberg, (1965). RSE items were to represent a continuum of self-worth statements ranging from statements that are endorsed even by individuals with low self-esteem to statements that are endorsed only by persons with high self-esteem. The present scale has ten Likert type items answerable on a four point scale from strongly agree to strongly disagree. The scale ranges from 0-30.scores between 15 and 25 are within normal range; and below 15 suggest low self-esteem.Reliability:80.

5. Employee Mental Health Inventory:_This inventory was developed by Jagadish (2001).A set of 24 items answerable in yes/no category where high score indicates better mental health and vice versa. The reliability coefficient was found to be 0.66 .

\section{RESULTS AND DISCUSSION}

To fulfill the main objective of the present study, the obtained data were subjected to a number of statistical analyses by using Statistical Package for Social Sciences (SPSS 13.0 version).Descriptive statistics, z-ratio test and Pearson Product Moment Correlation were used. To know if the predictor variable did contribute differentially, Multiple Regression Analysis was employed. The results of various analyses have been presented in separate headings.

(c) The International Journal of Indian Psychology, ISSN 2348-5396 (e)| ISSN: 2349-3429 (p) | 170 
Role of Job Satisfaction in Managing Sexual Satisfaction, Self Esteem and Mental Health at Work Place

Table-1, Means\& S.D.'S Of All the Research Variables

\begin{tabular}{|l|l|l|l|l|l|l|l|l|l|l|l|l|l|}
\hline & \multicolumn{2}{|l|}{ Sexual Satisfaction } & \multicolumn{3}{l|}{ Self Esteem } & \multicolumn{3}{l|}{$\begin{array}{l}\text { Mental } \\
\text { Health }\end{array}$} \\
\cline { 2 - 14 } & M & F & C & M & F & C & M & F & C & M & F & C \\
\cline { 2 - 14 } & 147.10 & 166.06 & 110.65 & 28.80 & 30 & 29.79 & 16.60 & 15.57 & 15.69 & 96.90 & 92.10 & 156.97 \\
\hline S.D & 30.04 & 46.39 & 33.23 & 6.16 & 6.08 & 5.78 & 3.02 & 3.80 & 3.48 & 27.31 & 36.02 & 36.64 \\
\hline
\end{tabular}

$\mathrm{M}=$ Male $\mathrm{F}=$ Female $\mathrm{C}=$ Clubbed Sample(Male and Female both)

$\mathrm{N}=150$,Male $=75$,Female $=75$

\section{Descriptive Statistics}

Table 1 presents the Mean and standard deviations of all the observed variables. Descriptive statistics was worked out to know the pattern of score distribution. A perusal of table 1 reveals that the mean score on Sexual Satisfaction is 110.65 with the standard deviation of 33.23.The mean score of Self Esteem is 29.79 with the SD of 5.78.The mean \& SD of Mental Health are 15.69 and 3.48 respectively on Job Satisfaction the mean score was 156.97 with the SD of 36.64 .

Table-2, Z-Ratios Speaking About Significance Of Differences Between Males \& Females On All The Research Variables

\begin{tabular}{|l|l|l|}
\hline Independent Variables & Obtained z value & Comments \\
\hline (Sexual Satisfaction) & 0.34 & Insignificant(at both level) \\
\hline (Job Satisfaction) & 0.11 & Insignificant(at both level) \\
\hline (Self Esteem) & 0.25 & Insignificant(at both level) \\
\hline (Mental Health) & 0.21 & Insignificant(at both level) \\
\hline
\end{tabular}

Significance Value: 1.96 at .05 level/2.58 at .01 level

\section{Parametric Statistics:}

Since no single $\mathrm{Z}$ ratio did come out to be statistically significant in Table 2.As such, the male \& female samples were clubbed together into one single pool of subjects' .Because the research hypotheses 1, 2 and 3 had to be rejected as the obtained z-ratios were below the critical value of (1.96) at 0.05 level of probability as well as of (2.58) at 0.01 level of probability. Thus next step that is computation of $r$ values was under taken to know the nature of relationship between each independent variable and the dependant variable considered at one time. Findings have been presented in table 2 below.

(c) The International Journal of Indian Psychology, ISSN 2348-5396 (e)| ISSN: 2349-3429 (p) | 171 
Role of Job Satisfaction in Managing Sexual Satisfaction, Self Esteem and Mental Health at Work Place

Table-3, Showing Inter Correlation Matrix

\begin{tabular}{|l|l|l|l|l|}
\hline Variables & Job satisfaction & $\begin{array}{l}\text { Sexual } \\
\text { satisfaction }\end{array}$ & Self Esteem & Mental Health \\
\hline Job satisfaction & 1.00 & $0.725^{* *}$ & $0.489 * *$ & $0.424^{* *}$ \\
\hline $\begin{array}{l}\text { Sexual } \\
\text { satisfaction }\end{array}$ & $0.725^{* *}$ & 1.00 & $0.550^{* *}$ & $0.457^{* *}$ \\
\hline Self Esteem & $0.489^{* *}$ & $0.550^{* *}$ & 1.00 & $0.680^{* *}$ \\
\hline Mental Health & $0.424^{* *}$ & $0.457^{* *}$ & $0.680^{* *}$ & 1.00 \\
\hline
\end{tabular}

${ }^{* *} \mathrm{p}<0.01,{ }^{*} \mathrm{p}<0.05 ; \mathrm{N}=150 \mathrm{DF}($ degrees of freedom $)=(\mathrm{n}-2)=(150-2)=148$

In this certain DF; the correlation coefficient values(r) at the (0.05) \& (0.01) levels of significance are 0.159 and 0.208 respectively with 148 degrees of freedom.

Correlations among all the 4 variables were computed by Pearson's Product Movement method. It was aimed at examining the degree of association between the measures of Sexual Satisfaction, Self Esteem, Mental Health and Job Satisfaction. A careful inspection of intercorrelation matrix (Table - 3) reveals that all the variables correlate significantly with each other. The inter-correlation between Sexual Satisfaction \& Job Satisfaction 0.725, which is highly positive and significant at 0.001 probability level. It shows that the people who are having high Job Satisfaction are having likely to have high sexual satisfaction, high self-esteem and a high or positive mental health. Develop Sexually Satisfied. The Positive Inter correlation between the measures of Job Satisfaction \& Self Esteem, Job Satisfaction \& Mental Health are 0.489 and 0.424 respectively are also highly significant. Again the moderate positives inter correlation between Sexual Satisfaction \&Self Esteem is 0.55 and Sexual Satisfaction \& Mental Health is 0.457 respectively, both are significant at .001probability level. And lastly the inter correlation between Self Esteem \& Mental Health is 0.680 is also positive as well as significant at .001 level of significance.

\section{Regression Analysis}

Regression analysis was computed to assess the strength of relationship between dependent variable and a set of independent variables. Regression Analysis provides an opportunity with little ambiguity to assess the importance of each of the predictors to the overall criterion variables. The results of regression analysis for the dependent variable Job Satisfaction (JS) are presented in table 4. It is clear from the results that the regression analysis had shown that for all three variables (Sexual Satisfaction, Self Esteem \& Mental Health); hence each of them was significant predictor of Job Satisfaction (JS). In Overall the three predictors contributed Multiple $\mathrm{R}$ of .735. The $\mathrm{F}$ ratio computed for the significance of multiple $\mathrm{R}$ is 57.207 , which is significant at .001 probability level.

(C) The International Journal of Indian Psychology, ISSN 2348-5396 (e) | ISSN: 2349-3429 (p) | 172 
Role of Job Satisfaction in Managing Sexual Satisfaction, Self Esteem and Mental Health at Work Place

Table-4, Final Summary Of Regression Analysis Dependent Variable: Job Satisfaction

\begin{tabular}{|l|l|l|l|l|l|}
\hline Multiple R & $\mathbf{0 . 7 3 5}$ & & Df & SS & MS \\
\hline R Square & 0.540 & Regression & 3 & 108094.982 & 36031.661 \\
\hline $\begin{array}{l}\text { Adjusted R } \\
\text { Square }\end{array}$ & 0.531 & Residual & 146 & 91957.851 & 629.848 \\
\hline $\begin{array}{l}\text { Standard } \\
\text { Error }\end{array}$ & 25.097 & F & 57.207 & P & 0.000 \\
\hline
\end{tabular}

Variables In Equation

\begin{tabular}{|l|l|l|l|l|l|}
\hline Variables & \multicolumn{1}{|c|}{ B } & \multicolumn{1}{c|}{ SE B } & Beta & t & \multicolumn{1}{|c|}{ P } \\
\hline $\begin{array}{l}\text { Sexual } \\
\text { Satisfaction }\end{array}$ & 0.712 & 0.075 & 0.646 & 9.528 & 0.000 \\
\hline Self Esteem & 0.537 & 0.521 & 0.085 & 1.030 & 0.305 \\
\hline Mental Health & 0.757 & 0.814 & 0.072 & 0.929 & 0.354 \\
\hline
\end{tabular}

The present investigation was conducted to find out the role of Sexual Satisfaction, Self Esteem \&Mental Health in producing job satisfaction at workplace. After analysing the results, it can be said that the original hypothesis of the present study -sexual Satisfaction, self-esteem and mental health can predict well enough the job satisfaction. But they predict differentially, not equally job satisfaction in order of predictive capacity mental health comes first, then sexual satisfaction and lastly come self-esteem.

\section{CONCLUSION}

Since there are no single Z scores of Job Satisfaction, Sexual Satisfaction, Self Esteem and Mental Health does come out to be statistically significant, so the male \& female samples is clubbed together into one single pool of subjects'. It can be concluded that there does exist a highly positive inter correlation between these 4 variables. And finally it is found in the present study that there is a definite role of Job Satisfaction in Managing Sexual Satisfaction, Self Esteem and Mental Health of the IT employees at Work Place in Kolkata.

\section{Limitation Of The Study}

1) Respondent's opinions are dynamic; they keep changing from time to time.

2) Some of the respondents might not have given the actual information due to fear of being disclosed.

3) The results are confined to only few numbers of inviduals and cannot be generalised to a huge population.

4) The study was conducted with the limited number of respondent due to time constraint.

5) Satisfaction level to various factors may differ from person to person.

(c) The International Journal of Indian Psychology, ISSN 2348-5396 (e)| ISSN: 2349-3429 (p) | 173 
Role of Job Satisfaction in Managing Sexual Satisfaction, Self Esteem and Mental Health at Work Place

\section{Acknowledgments}

The author appreciates all those who participated in the study and helped to facilitate the research process.

\section{Conflict of Interests}

The author declared no conflict of interests.

\section{REFERENCES}

Antonella Gigantesco, Angelo Picardi, Elvira chiaia, Andrea Balbi, Pierluigi Morosini (2003). "Job Satisfaction among Mental Health Professionals in Rome, Italy". Journal of Community Mental Health, August 2003, Vol 39, issue 4, pp. 349-355.

Bond, Frank W; Bunce, David (2003). "The Role of Acceptance and Job Control in Mental Health, Job Satisfaction, and Work Performance”. Journal of Applied Psychology, Vol 88(6), Dec 2003, 1057-1067

Fariba Ebrahimi Tazekand, Narges Nafar, Raziye Keramati (2013) "The relationship between marital satisfaction and job satisfaction”. Life Science journal 2013.

Hamid Reza Alavi, Mohammad Reza Askaripur (2015). "The Relationship between Self-Esteem and Job Satisfaction of Personnel in Government Organizations”. Journal Citation Reports. 2015 Web of Science Data.

Janyam K. (2009) “The Influence of Job Satisfaction on Mental Health of Factory Workers”. The Internet Journal of Mental Health.2009; Vol 7, No 1.

Kaheh Davood, Heiivad Tayebeh (2012) "The relationship between Job Satisfaction and Mental Health oh Staff ".Payesh May-June 2012,Vol 11,No 3; Pages(s) 391 To 397.

Nick Drydakis, Anglia Ruskin University and IZA(2014)“Effect of Sexual Orientation on Job Satisfaction”. Discussion Paper No. 8045 March 2014; Source: nick.drydakis@anglia.ac.uk.

Seyyed Hossein Hosseini Ghafari, Masoumeh Samii (2013). "The relationship between job satisfaction and Self-esteem in teachers: A case study in Aliabad University” Vol 2, No3(s). European Online Journal of Natural and Social Sciences.

How to cite this article: A Bhattachajee, A Kundu, I Mukherjee (2016), Role of Job Satisfaction in Managing Sexual Satisfaction, Self Esteem and Mental Health at Work Place, International Journal of Indian Psychology, Volume 3, Issue 4, No. 67, ISSN:2348-5396 (e), ISSN:2349-3429 (p), DIP:18.01.192/20160304, ISBN:978-1-365-39397-6 